\title{
Cholesterol oxidation: Health hazard and the role of antioxidants in prevention
}

\author{
ALFONSO VALENZUELA*, JULIO SANHUEZA and SUSANA NIETO \\ Laboratory of Lipids and Antioxidants, INTA, University of Chile, Santiago, Chile
}

\begin{abstract}
Cholesterol is a molecule with a double bond in its structure and is therefore susceptible to oxidation leading to the formation of oxysterols. These oxidation products are found in many commonly-consumed foods and are formed during their manufacture and/or processing. Concern about oxysterols consumption arises from the potential cytotoxic, mutagenic, atherogenic, and possibly carcinogenic effects of some oxysterols. Eggs and egg-derived products are the main dietary sources of oxysterols. Thermally-processed milk and milk-derived products are another source of oxysterols in our diet. Foods fried in vegetable/animal oil, such as meats and French-fried potatoes, are major sources of oxysterols in the Western diet. Efforts to prevent or to reduce cholesterol oxidation are directed to the use of antioxidants of either synthetic or natural origin. Antioxidants are not only able to inhibit triglyceride oxidation, some of them can also inhibit cholesterol oxidation. Among synthetic antioxidants 2,6-ditertiarybutyl-4-methylphenol (BHT), and tertiary butylhydroquinone (TBHQ) can efficiently inhibit the thermalinduced oxidation of cholesterol. Some natural antioxidants, such as alpha- and gamma-tocopherol, rosemary oleoresin extract, and the flavonoid quercetin, show strong inhibitory action against cholesterol oxidation.
\end{abstract}

Key terms: Cholesterol, cholesterol oxidation, oxysterols, synthetic antioxidants, natural antioxidants.

BIOLOGICAL IMPORTANCE OF CHOLESTEROL

Sterol cholesterol (cholest-5-en- $\beta$-ol) is an essential metabolite required for major biological functions, such as the cell membrane structure where the steroid forms, together with phospholipid molecules, the integral part of the lipid bilayer (Spector \& Yorek, 1985). Cholesterol is inserted into membrane bilayers with its long axis perpendicular to the plane of the membrane, preventing the crystallization of fatty acyl chains by fitting between them (Yeagle, 1985) and modifying the activity of membranebounded enzymes (Valencia et al., 1999). Cholesterol also provides the structural scaffolding for the synthesis of steroids and steroid hormones, and for the biosynthesis of bile and bile acid salts. Sterol plays also an important role in embryonic development (Roux et al., 2000).
Organisms obtain cholesterol through biosynthesis and diet. Cholesterol biosynthesis is a highly-regulated process that occurs in almost all animal tissues, but in higher mammals the liver, the adrenal gland, the ovaries, and testis show the most significant biosynthetic activity. Bile is the major excretion route of cholesterol from the body, predominantly as unesterified cholesterol (Robins \& Brunengraber, 1982). In the adult human, approximately $400 \mathrm{mg}$ of cholesterol per day are converted to bile acids and only approximately $50 \mathrm{mg}$ are converted to hormones (Ishibashi et al., 1996).

\section{CHOLESTEROL OXIDATION AND AUTOXIDATION}

Cholesterol is a molecule with an unsaturated bond at position $\Delta 5-6$ of the sterol nucleus, therefore it is prone to 
oxidation (Maerker, 1987). The molecule undergoes autoxidation by a free-radical mechanism leading to the formation of hydroperoxides and then to a number of oxidation products, the so-called oxysterols. These oxidation products are a group of sterols similar in structure to cholesterol, but that contain an additional oxygen function such as an hydroxyl group, ketone group, or an epoxide group at the sterol nucleus or at the side chain of the molecule. Many different oxysterols (up to 70) have been identified (Schroepfer, 2000), and many probably remain to be identified. The physical state of cholesterol greatly influences the types of oxidation products. The auto-oxidation of solid cholesterol has been extensively studied and is welldocumented (Korahani et al., 1982). When cholesterol is in a crystalline state and in the presence of air, the oxidation reaction is governed by the arrangement of molecules in the crystal. Cholesterol molecules are arranged into double layers with the 3-hydroxyl groups in juxtaposition and side chain exposed.

Oxidation of cholesterol may be initiated by polyunsaturated fatty acid oxidation (Kubow, 1993). Interaction of triglycerides with cholesterol may accelerate the oxidation of the sterol, and cholesterol may also influence triglyceride oxidation (Kim \& Nawar, 1991). Peroxides formed on polyunsaturated fatty acids during lipid oxidation may substract a hydrogen from the $\Delta 5-6$ double bond, allowing the formation of a free radical into the cholesterol structure (Paniangvait et al., 1995). This free radical may migrate to the position 4 or 7 of rings A and B respectively, allowing the reaction of molecular oxygen at the position 4, 5, 6 or 7 . However, the most stable and preferred position is at carbon 7 , where the hydroperoxide, may form either a hydroxyl derivative by decomposition (7 $\alpha$-hydroxycholesterol or 7 B-hydroxycholesterol) or a ketoderivative by dehydration (7ketocholesterol) (Kubow, 1991). Another possibility is the reaction of molecular oxygen free radicals directly with the double bond, forming a 5, 6-epoxycholesterol by addition, which by further dehydration can be transformed into a triol (cholestane- $3 \beta$, $5 \alpha, 6 \beta$-triol). Oxidation at the lateral chain may produce either the 20-hydroxy- or the 25-hydroxycholesterol- derivative. Oxygen free-radicals show different behavior as inductors of cholesterol oxidation. While superoxide free-radicals are ineffective in inducing oxidation, the presence of the free radical together with hydrogen peroxide, the product of the dismutation of the superoxide free-radicals, exerts a strong pro-oxidative effect (Lee et al., 1977). This means that hydroxyl free-radicals formed from the reaction of superoxides with hydrogen peroxide may be involved in the oxidation mechanism (Sevanian \& McLeod, 1987). The structure of the main oxysterols which can be identified in traditional Western foods are depicted in Figure 1.

ANALYTICAL PROCEDURES TO EVALUATE OXYSTEROLS

Due to the presence of low concentrations (ppm or $\mathrm{ppb}$ ) of oxysterols in foods or in animal tissues, isolation procedures that separate the sterol oxidation products from other interfering substances and quantification of oxysterols are difficult analytical procedures. Usually these procedures involve two steps: a separation of the sterol fraction from other lipid materials, followed by the removal of cholesterol. The initial separation can be accomplished either by saponificationextraction or by column chromatography on silica (Park \& Addis, 1992). This must followed by thin-layer or reversed-phase column chromatography to remove cholesterol that would interfere with subsequent analyses. Previous workers in the field have employed saponification of the extracted lipids with hot alkali as an important part of the enrichment procedure. This step frees the bulk of the lipids from the sterol residue and also converts esterified cholesterol to the free sterol. Nevertheless, some important cholesterol oxides, notably 7-ketocholesterol, have long been known to be unstable to hot aqueous alkali. The artifactual formation of cholesterol oxidation products has been reported during the course of the hot saponification procedure (Park \& 
Addis, 1992). Cold saponification may avoid these problems and is now the standard procedure for the extraction of oxysterols previous to analytical separation (Park \& Addis, 1985; Zhang et al., 1992).

Analytical procedures for the determination of the extent of cholesterol oxidation in food, especially in heated and/ or stored foods with high cholesterol content, include capillary gas-chromatography (GC) (Addis et al., 1989; García \& Maraschiello, 1997), GC-mass spectrometry (GC-MS) (Park \& Addis, 1986; Osada et al., 1993), and high performance liquid chromatography (HPLC) (Park \& Addis, 1985). GC has been used by several researchers because it allows the rapid separation and identification of up to 17 different oxysterols. The procedure requires the previous derivatization of the sterols with hexamethyl trichloro methylsilane to form the silyl-esters. To confirm identification by GC, equipment can be coupled to a MS. Taking into account that HPLC greatly simplifies the quantification procedure and introduces fewer artifacts, normal phase (NP) and reversed-phase (RP) methods have been applied to the separation of oxysterols by several researchers (Park \& Addis, 1985; Park \& Addis, 1992; Smith, 1996). NP-liquid chromatography systems generally proved to be more effective than $\mathrm{RP}$, but full resolution over the entire polarity range of oxidation products was not achieved (Park \& Addis, 1985). Particle beam HPLCMS is another analytical alternative for the detection of oxysterols at the nanogram level has been successfully applied by Careri et al., (1998). The excellent revisions of Park \& Addis (1992) and Schroepfer (2000) summarizes the main analytical procedures for assessing cholesterol oxides in lipid samples.

\section{OXYSTEROLS IN COMMONLY CONSUMED FOODS}

It has been estimated that approximately $1 \%$ of the cholesterol consumed in a mixed Western diet is oxidized cholesterol (van de Bovenkamp et al., 1988). Dietary sources of oxysterols are cholesterol-rich

Figure 1.

MAIN CHOLESTEROL OXIDES (OXYSTEROLS)
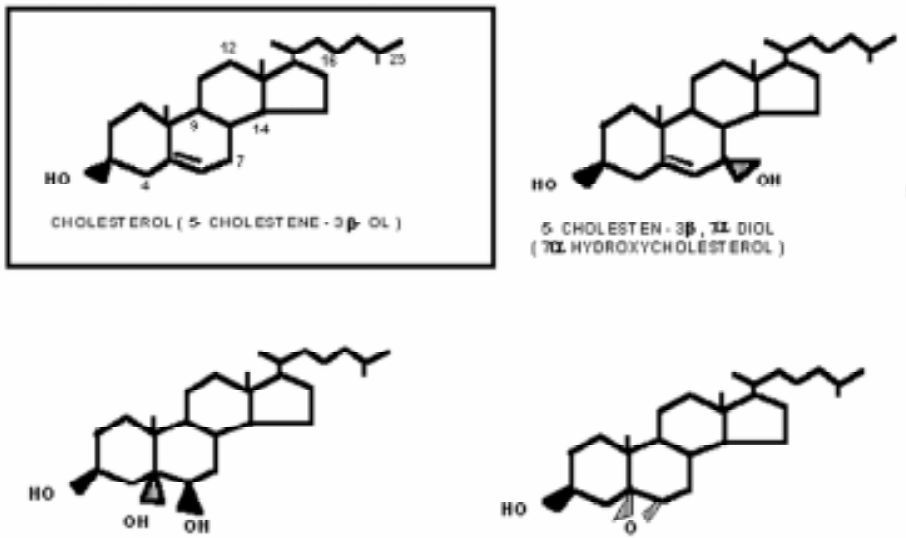

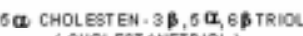
(CHOLESTANETRIOL)

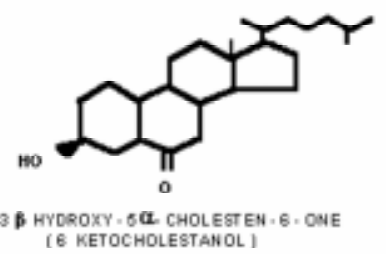

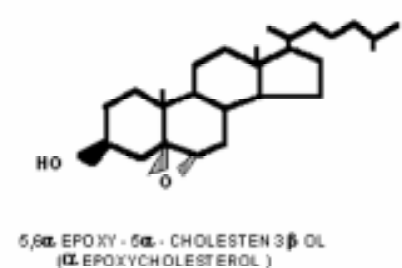
(I. EPOXYCH OLESTEROL)

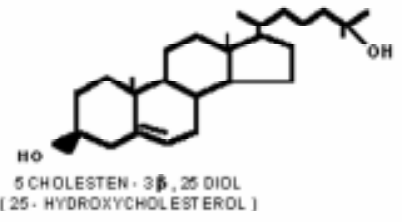

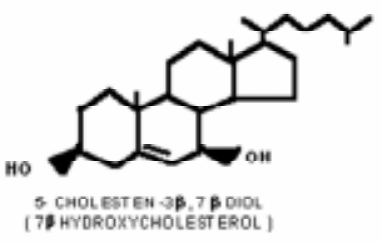
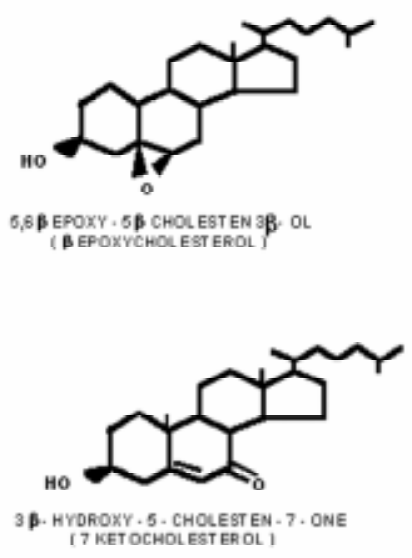
foods, such as dairy, processed eggs, and meat products. Cholesterol containing foods, when subjected to high temperatures during manufacture and/or processing may form variable amounts of oxysterols, depending on the analytical method applied for their identification, as was discussed above. The most commonly detected oxysterols in foods are the major products of cholesterol oxidation: $7 \alpha$-hydroxycholesterol, $7 \beta$ hydroxycholesterol, $\alpha$-epoxycholesterol, $\beta$ epoxycholesterol, and 7-ketocholesterol, which can be found in amounts ranging from nano gr to $\mathrm{mg} / \mathrm{gr}$ of sample (Sander et al., 1989; Paniangvait, et al., 1995).

\section{Eggs and egg-derived products}

Foods that are naturally characterized by high cholesterol content are major sources of oxysterols when processed, such as eggs and egg-derived products. An average egg contains 200-220 mg cholesterol, which is about twice the cholesterol content of butter and freeze-dried meat products, and about 5-10 times more cholesterol than is found in most dairy products. Dried whole egg or dried egg yolk, but not fresh egg yolk, are significant sources of oxysterols when used in the manufacture of convenience foods (Missler et al., 1985; Galobart et al., 2002). Oxysterol content of eggs (dehydrated, dried) are in the range of 0.05-1.50 ug/g, and for egg-yolk (dehydrated or dried) amounts are 15-120 ug/g (Morgan \& Armstrong, 1992). Irradiation applied to the control of Salmonella considerably increases the amount of oxysterols in egg yolk powder from $10 \mathrm{ug} / \mathrm{g}$ to $470 \mathrm{ug} / \mathrm{g}$ on average (Du \& Ahn, 2000).

\section{Dairy products}

Several dairy products and milk powder are reported to contain oxidized cholesterol after processing (Dionisi et al., 1998). The oxysterols found in these products are the same as those in processed eggs. However, fresh milk contains 0 or only trace amounts of cholesterol oxides, which means that processing (e.g high temperature) is the main source of oxysterols (Angulo et al., 1997). Other milk-derived products such as cheeses, yogurt, and evaporated milk, contain very low amounts of cholesterol oxides. The oxysterol content of milk powder is in the range $1.0-2.5 \mathrm{ug} / \mathrm{g}$. Dehydrated cheese has 8-15 ug/g; skimmed milk powder, 0.01-0.1 $\mathrm{ug} / \mathrm{g}$; and whole milk powder, 0.2-0.8 ug/g (Paniangvait et al., 1995). The amount of oxysterols present in these products depends on the processing temperature and the length of the storage period (Nourooz-Zadeh \& Appelqvist, 1988).

\section{Meat and meat-derived products}

The mean lipid content of lean meat is $10 \%$, wet weight basis, of which triglycerides and phospholipids are major components and cholesterol is a lesser component, ranging from 50 to $89 \mathrm{mg}$. The main source of oxysterols in meats (from bovine, poultry and porcine origin) is heat processing, mainly over-heating. Fresh meat and fresh meat products contain 0 or trace amounts of cholesterol oxides. Oxysterols contained in cooked meat range from 180-1900 ug/g (Paniangvait et al., 1995).

\section{Other food products}

It has been proposed that frying in animal/ vegetable oils is an major source of oxysterol in the Western diet. The primary target are French fried potatoes, which together to other deep-fried foods cooked in animal/vegetable fat are considered the main source of oxysterols in the U.S. and Latin America. The oxysterol content of potatoes fried in tallow or vegetable/animal oil may be in the range of $1.4 \mathrm{mg} / \mathrm{g}$ to 16.7 $\mathrm{mg} / \mathrm{g}$, depending on the origin and/or the animal fat content of the frying oil (Paniangvait et al., 1995).

\section{ABSORPTION AND BIOLOGICAL EFFECTS OF OXYSTEROLS}

Oxysterols that tend to be more polar than cholesterol may also be absorbed in the 
intestinal track by a mechanism similar to that of cholesterol absorption (Emmanuel et al., 1991); oxysterols may form a structural part of the mixed micelles in the small intestinal lumen. Oxysterols may enter the blood circulation with dietary cholesterol and biliary cholesterol (endogenous cholesterol) as part of chylomicron structure (Linseisen \& Wolfran, 1998). Because of the similarity in structure between oxysterols and cholesterol, it has long been assumed that transport in serum would by similar (Peng et al., 1985). Oxysterols are also transported by low density lipoproteins (LDL), as is cholesterol, and there is evidence that high density lipoproteins (HDL), which perform reverse cholesterol transport, are also involved in the transport of oxysterols from tissues to the liver (Streuli et al., 1981; Robins \& Fasulo, 1997; Rigotti, 2000). Although a major percentage of oxysterol is derived from dietary sources, it has been suggested that some of the circulating oxysterols may be formed from lipoprotein oxidation at the blood stream and/or at the intracellular metabolism (Linseisen et al., 1998). Oxysterols are able to pass through lipophilic membranes much more quickly than cholesterol does (Björkhem, 2002), and they may also be formed by intracellular enzymatic reactions. Parenchymal hepatocytes have been thought to be the primary, if not the sole, cell type possessing functional enzyme system that could convert cholesterol into oxidized derivatives, namely the cytochrome P-450 system (Boström, 1994). Within the cytochrome P-450 family, 27-hydroxylase activity is an important enzyme responsible for the hydroxylation of cholesterol sidechain (Cali \& Russell, 1991). Available data suggest that enzymatically-generated oxysterols may account for a significant percentage of oxysterols found in serum and other tissues (Linseisen et al., 1998).

REGULATORY FUNCTIONS OF OXYSTEROLS AT CELLULAR LEVEL

Oxysterols are considered cytotoxic (Leland e al., 1989), although some researchers have postulated regulatory functions for some oxysterols at the intracellular level (Luu \& Moog, 1991; Lund \& Björkhem, 1995; Böjrkhem, 2002). 3-Hydroxy-3-metilglutaryl coenzyme A reductase (HMG-CoA red), the enzyme catalyzing the rate-limiting step in cholesterol biosynthesis, is among the most highly-regulated enzymes found in nature. Many oxysterols are potent competitive inhibitors of HMG-CoA red at concentration levels of less than $100 \mathrm{nM}$ (Tanaka et al., 1983). However, the regulatory action of oxysterols on the enzyme is extended not only to its activity, but also on its expression at genetic level. Oxysterols are capable of inhibiting the synthesis of HMG-CoA reductase at the transcriptional level by decreasing the reductase mRNA and the rate of protein synthesis, and at the post-transcriptional level by modifying the anchoring of the enzyme at the smooth endoplasmatic reticulum membrane (Edwards \& Ericsson, 1999). Cholesterol biosynthesis is also regulated by transcription factors named steroid regulatory element binding proteins (Brown \& Goldstein, 1997). A newlydiscovered transcription factor, identified as LXR (Björkhen \& Diczfalusy, 2002), regulates the catabolic degradation of cholesterol by activation of the gene controlling cholesterol $7 \alpha$-hydroxylase, the rate-limiting enzyme in the formation of bile acids (Ishibashi et al., 1996). Oxysterols may bind to LXR, thereby inducing the transcription of cholesterol 7 $\alpha$-hydroxylase, and thus increasing the removal of cholesterol as bile acids (Lehmann et al., 1997).

Oxysterols are also potent regulators of intracellular cholesterol esterification (Brown et al., 1975). Membrane-bound enzyme acetyl-CoA:cholesterol acyl transferase (ACAT), which is responsible for the intracellular esterification of cholesterol, is strongly activated by oxysterols (Saucier et al., 1985). Because cholesterol achieved comparable enhancement of ACAT only at much higher concentrations, it has been speculated that the true activators of the enzyme in mammalian cells are oxysterols rather than 
cholesterol by itself (Drevon et al., 1980). Modulation of ACAT activity is probably exerted at the post-translational level (Kushuhara et al., 1992; Leonarduzzi et al., 2002).

\section{OXYSTEROLS AND ATHEROGENESIS}

The cytotoxic, mutagenic and probably carcinogenic effects described for some oxysterols have been observed in in vitro models. However, the atherogenic action of oxysterols has been demonstrated in both in vitro and in vivo study models, to be the best-characterized pathological expression of cholesterol oxidation (Staprans et al., 1998; Leonarduzzi et al., 2002) and comparable to the atherogenic action of trans fatty acid isomers (Valenzuela \& Morgado, 1999).

Atherosclerotic lesions not only contain cholesterol, but also a series of oxysterols (Ostlund et al., 2002). In the widely accepted model for the pathogenesis of atherosclerosis, the impact of oxidatively modified low-density lipoprotein (LDL) particles is very important (Brown \& Jessup, 1999). In addition to polyunsaturated fatty acids and apolipoproteins, the cholesterol moiety of LDL can undergo oxidative damage, resulting in different effects on target cells (e.g., macrophages, aortic smooth muscle cells) that may promote the development of atherosclerosis (Chang et al., 1997). Oxidized LDL is potentially more atherogenic than native LDL in several ways: 1.- It is chemotactic for circulating monocytes; 2.- It is an inhibitor of the motility of resident macrophages; 3 .- It is cytotoxic for cell in culture; 4.- It can stimulate release of a chemotactic factor from endotelial cells (Rong et al., 1999). Many of these oxidized LDL characteristics are attributed to the oxysterol content of the lipoprotein (Leonarduzzi et al., 2002). In vivo oxysterols are formed either enzymatically or via autoxidation of cholesterol. Although it the most prevalent means of LDL-cholesterol oxidation in vivo has not been established, the contribution of free iron to oxidation (through nonenzymatically autoxidation), is considered to be significant (Schroepper, 2000). The contribution of dietary oxysterols to the total amount of oxysterol measurable in plasma and lipoproteins of human is still unclear.

\section{OXYSTEROL METABOLISM}

\section{Oxysterols and bile acid synthesis}

Most sterols, including cholesterol, are eliminated from the body through bile secretion. Synthesis of bile acids occurs in the liver through $7 \alpha$-hydroxylation of cholesterol; the oxysterol, $7 \alpha$ hydroxycholesterol, and once formed can then be used to synthesize both cholic acid, the most common bile acid, and chemodeoxycholic acid (Morel \& Lin, 1996). It is generally accepted that the catabolism of oxysterols is similar to that of cholesterol (Björkhem, 2002). However, it is not clear if oxysterols and cholesterol share the same pathways for bile acid synthesis. However it has been proposed that a family of P-450 $7 \alpha$-hydroxylases isozymes catalyze oxysterol metabolism independently from the P-450 hydroxylases that catalyze cholesterol metabolism (Javitt, 1990).

\section{Oxysterols and steroidogenesis}

As with cholesterol, which serves as a precursor for many steroid hormones, there is evidence that oxysterols, especially those with a hydroxyl group on the side chain, can serve as substrates for steroid hormone synthesis in steroidogenic cells (Chaudhary et al., 1992). Tuckey et al., (1992) demonstrated that hydroxycholesterol were comparable to cholesterol as substrates for side chain cleavage.

\section{Esterification of oxysterols}

There is ample evidence that oxysterols are readily susceptible to esterification reaction. Fatty acid esters are the predominant form of oxysterols found in 
extrahepatic tissues such as the aorta (Björkhem, 1992), and these esters are also found in plasma associated with various lipoproteins (Peng, et al., 1985). Using purified lecithin:cholesterol acyltransferase (LCAT), the enzyme responsible for esterification of cholesterol in serum, or the non-lipoprotein fraction of serum as a source for the enzyme, in vitro studies have shown that oxysterols are readily esterified and that the esterification can be inhibited by agents known to inhibit the esterification of cholesterol (Lin \& Morel, 1996). Similarly, tissue culture studies have shown that oxysterols can be esterified by ACAT (Lichtenstein \& Brecher, 1983). Although oxysterols have an additional oxygen function that might be available for esterification, fatty acid monoester formation, most likely at $3 ß$-position of the sterol nucleus, appears to predominate (Lin \& Morel, 1996).

\section{INHIBITION OF OXYSTEROL FORMATION, THE ROLE} OF ANTIOXIDANTS

In light of the potentially dangerous effects of oxysterols for human health, efforts to prevent or to reduce oxysterol consumption are now currently begin made. As processed foods of animal origin are the main dietary sources of oxysterols, prevention of its formation during manufacture, processing, storage, or culinary preparation, is of importance. Antioxidants, both of synthetic or natural origin, are widely applied to prevent lipid oxidation in processed foods, raw materials, or fats and oils used in manufacture (Valenzuela \& Nieto, 1996). However, antioxidant action is directed to prevent or delay fatty acid oxidation. The effect of antioxidants to prevent oxysterol formation has scarcely been investigated.

Antioxidants are organic lipid- or watersoluble substances that can scavenge the active forms of oxygen involved in the initiation steps of the oxidation, or break the oxidative chain reaction. Antioxidants may react with the fatty acid peroxy radicals to form stable antioxidant radicals, which are either insufficiently reactive for further reactions or form non-radical products
(Valenzuela \& Nieto, 1996). The most widely used synthetic antioxidants in human foods are 2,6-di-tertiarybutyl-4methylphenol (BHT), tertiarybutyl-4hydroxyanisole (BHA), tertiary butylhydroquinone (TBHQ), and the npropyl ester of 3,4,5-trihydroxybenzoic acid (propyl gallate, PG) (Dorko, 1994). Animal feed also uses 6-ethoxy-1, 2-dihydro-2,4trimethylquinoline (ethoxyquine, EQ), which is not allowed for human consumption. These synthetic antioxidants have been used for a long time, although recently concerns have arisen due to the possible potential toxicity in some (Lachance et al., 2001). Natural antioxidants, which are present in variable amounts in vegetables such as fruits, leaves, flowers, roots, grains, and seeds, have gained prominence as alternatives to synthetic antioxidants (Aruoma, 1997). Research interest in the properties and occurrence of natural antioxidants focus on vitamin E (mainly the alpha, beta, and gamma tocopherol homologous), some herbs extracts, such as rosemary extract, carotenoids, and various flavonoids (Valenzuela, 2002; Valenzuela et al., 2003).

Since cholesterol oxidation proceeds via a free radical mechanism, similar to polyunsaturated fatty acid oxidation (Kubow, 1993), antioxidants used to inhibit general fat and oil oxidation are also able to prevent or retard cholesterol oxidation. However, results are diverse and sometimes contradictory. Morgan \& Armstrong (1992) demonstrated that BHT, BHA, and PG were slightly effective in slowing hydrogen peroxide-induced cholesterol oxidation in egg yolk during spray drying. Huber et al. (1995) showed significant inhibitory effect of BHA on oxysterol formation when spraydried egg yolk oxidation is catalyzed by $\mathrm{Cu}^{2+}$ during accelerated storage at $60^{\circ} \mathrm{C}$. Maerker \& Unruh (1986) observed that BHT is unable to inhibit cholesterol oxidation during hot saponification of triglycerides. The same antioxidant cannot inhibit oxysterol formation from irradiated egg yolk powder (Morgan \& Armstrong, 1992). The effect of the synthetic antioxidants BHT, BHA, TBHQ, PG and EQ, on cholesterol oxidation using a vegetable oil 
as substrate for oxidation and monitored under the Rancimat 679 test conditions was recently communicated (Valenzuela et al., 2002). BHT and TBHQ act as the most effective inhibitors; BHA and EQ are less effective, and $P G$ are unable to inhibit cholesterol oxidation.

In addition to possessing vitamin $\mathrm{E}$ function, tocopherols are the major natural antioxidants in foods and are important for the stability of vegetable oils (Valenzuela $\&$ Nieto, 1996). This antioxidant aspect of tocopherol chemistry has been extensively studied, especially regarding the relative antioxidant activity of $\alpha$-tocopherol, and less extensively for the $\gamma$-, and $\delta$-tocopherol homologues. While some researchers claim that $\gamma$-tocopherol is a better antioxidant than $\alpha$-tocopherol (Pokorny, 1991; Lampi et al., 1999), other researchers reported a better effectiveness of a-tocopherol as antioxidant (Yoshida et al., 1993). Differences are probably due to the different oxidation models used to assess the antioxidant activity of these tocopherols. It is generally accepted that $\alpha$-tocopherol has a higher ability for hydrogen donation than its $\gamma$-homologue. The latter was often found to be a better antioxidant in pure liquidphase systems, especially when comparisons were made using high concentrations. The antioxidant effect of $\alpha$-tocopherol against cholesterol oxidation has been studied in models of diverse complexity, such as spray-dried egg yolk, fish oil, sunflower oil, and palm oil (Li et al., 1996), or dehydrated and powdered anchovy (Shozen et al., 1997). For all these models, $\alpha$ tocopherol has been identified as the most effective antioxidant, with better activity than other antioxidants, such as BHA or BHT.

Csallany et al., (2002) have recently demonstrated that $\alpha$-tocopherol, BHA, and BHT can inhibit the oxidation of cholesterol in the presence of superoxide anion, water, and hydrogen peroxide. In an in vivo model, Galobart et al (2002) demonstrated that feeding laying hens with linseed oil or sunflower oil with added $\alpha$-tocopheryl acetate may reduce cholesterol oxidation of spray-dried omega-6/omega-3 fatty acidenriched eggs during storage. Our team recently reported the effect of $\alpha-, \beta-, \gamma-$, and $\delta$-tocopherol on cholesterol-containing liposomes, when fatty acid and cholesterol oxidation is induced by $\mathrm{Fe}^{2}$ (Valenzuela et al., 2002a). Under these conditions, tocopherols exhibit different antioxidant effect. $\gamma$-Tocopherol acts as the strongest antioxidant, followed by $\alpha$-tocopherol. $\delta$ Tocopherol and $\beta$-tocopherol are devoid of antioxidant activity. Tocopherols having antioxidant activity proved to be more efficient in inhibiting oxysterol formation at the lateral chain of cholesterol (i.e, inhibition of $20-\mathrm{OH}$ and $25-\mathrm{OH}$ ) than at the nucleus of the sterol (i.e., 7 alpha-OH, 7 beta-OH, 5 alpha-3OH, and 7-keto) (Valenzuela et al., 2002a).

Rosemary extract is a food grade natural antioxidant oleoresin obtained from the leaves of the evergreen shrub rosemary (Rosmarinus officinalis. L) (Okamura et al., 1994). The extract contains four effective antioxidants: carnosol, rosmanol, isorosmanol, and rosemarydiphenol (Wu et al., 1982). When processed, these four compounds are odorless and tasteless diterpenolactones, and among these lactones, rosmaridiphenol and rosmanol, show stronger antioxidant activity than BHA and BHT. The effect of rosemary extract on cholesterol oxidation was recently assayed using highly purified soybean oil as a substrate for oxidation. Under these experimental conditions rosemary extract exerted a strong antioxidant effect by preventing both soybean oil oxidation and cholesterol oxidation (Valenzuela et al., 2002b).

Flavonoids comprise a well-known family of natural substances that exhibit antioxidant properties (Cook \& Samman, 1996; Heim et al., 2002). These structures are ubiquitous in photosynthesizing cells, seeds, fruits, pollen, and flowers (Havsteen, 1983). Flavonoids have been defined as "high level" antioxidants (Robak \& Gryglewski, 1988; Urquiaga \& Leighton, 2000). They act by scavenging those free radicals or exited forms of oxygen involved in the first stages of lipid oxidation, such as the singlet oxygen, the superoxide free radical or the hydroxyl free radical (Fraga et al., 1987). The effectiveness of some 
flavonoids as antioxidants for fats and oils has been previously demonstrated (Das \& Pereira, 1990; Nieto et al., 1993; Lotito \& Fraga, 2000). The effect of four flavonoids; quercetin, catechin, morin, and rutin, was recently assayed against cholesterol oxidation when oxidation was induced by temperature, and using soybean oil as substrate for oxidation (Valenzuela et al., 2002 b). Under these conditions, quercetin was highly effective in preventing cholesterol oxidation. Catechin also showed protective action, but less efficiently than quercetin. The other two flavonoids, morin and rutin, were devoid of antioxidant activity. The literature does not describe assays of cholesterol oxidation involving flavonoids as antioxidants, therefore substances such as quercetin and catechin, cannot be underestimated as future foodgrade antioxidants, and as inhibitors of temperature-induced cholesterol oxidation.

Information on the effect of natural antioxidants other than tocopherols on cholesterol oxidation is very limited. In the last two decades, interest in using natural ingredients in foods has increased dramatically. Many attempts have been made to replace synthetic antioxidants with natural products (Valenzuela et al., 2003). The emphasis given to natural antioxidants results from concerns over the toxicity of some synthetic antioxidants and from the research findings that point to a relationship between active dietary ingredients, such as natural antioxidants, and their protection of cells from free radical-induced oxidative stress in the human body (Fitch-Haumann, 1990).

\section{CONCLUDING REMARKS}

Cholesterol oxidation products can be potentially harmful to human health. These products are formed from cholesterolcontaining foods during processing, especially when high temperatures are applied during different stages of food manufacture. Parallel to the identification of these cholesterol-oxidized products that can be dangerous, and of their actions at the cellular level, it is necessary to make the effort to prevent oxysterol formation during the different stages of food processing or introducing it into the raw materials used in its manufacture. Both synthetic or natural antioxidants may allow this protection, some of which have demonstrated efficiency in inhibiting cholesterol oxidation in different experimental models. However further research must be conducted to characterize the best way to apply antioxidants for the prevention of cholesterol oxidation. This is a challenge for biochemists, food chemists, food ingineers, and processing technologists.

\section{ACKNOWLEDGMENTS}

The work of the authors is supported by FONDECYT, project 1990759 and 1020720, FONDEF, project ID-1125, Alltech Biotechnology (USA), and Ordesa SA (Spain).

\section{REFERENCES}

ADDIS PB, EMANUEL H, BERGMANN S, ZAVORAL J (1989) Capillary GC quantification of cholesterol oxidation products in plasma lipoproteins of fasted humans. Free Rad Biol Med 7: 179-182

ANGULO AJ, ROMERA JM, RAMÍREZ M, GIL A (1997) Determination of cholesterol oxides in dairy products. Effect of storage conditions. J Agric Food Chem 45, 4318-4323

ARUOMA OI (1997) Extracts as antioxidant prophylactic agents. INFORM 8: 1236-1242

BJÖRKHEM I (1992). Mechanism of degradation of the steroid side-chain in the formation of bile acids. J Lipid Res 33: 455-471

BJÖRKHEM I (2002) Do oxysterols control cholesterol homeostasis? J Clin Nutr 110: 725-730

BJÖRKHEM I, DICZFALUSY U (2002) Oxysterols, friends, foes, or just fellow passengers? Arterioscler Thromb Vasc Bio 22: 734-742

BOSTRÖN H (1994) Binding of cholesterol to cytochromes P-450 from rabbit liver microsomes. J Biol Chem 258: 15091-15094

BROWN MS, DANA SE, GOLDSTEIN JL (1975) Cholesterol ester formation in cultured human fibroblasts. Stimulation by oxygenated sterols. J Biol Chem 250: 4025-4027

BROWN MS, GOLDSTEIN JL (1997) The SREBP pathway: regulation of cholesterol metabolism by proteolysis of a membrane-bound transcription factor. Cell 89: 331-340

BROWN AJ, JESSUP W (1999) Oxysterols and atherogenesis. Atherosclerosis 142: 1-28 
CALI JJ, RUSSELL DW (1991) Characterization of human sterol 27-hydroxylase. A mitochondrial cytochrome P-450 that catalyzes multiple oxidation reactions in bile acid biosynthesis. J Biol Chem 266: 7774-7778

CARERI M, FERRETTI D, MANINI P, MUSCI M (1998) Evaluation of particle beam high-performance liquid chromatography-mass spectroscopy for analysis of cholesterol oxides. J Chromatog A 794: 253-262

CHANG YH, ABDALLA SP, SEVANIAN A (1997) Characterization of cholesterol oxidation products formed by oxidative modification of low density lipoproteins. Free Rad Biol Med 23: 202-214

COOK NC, SAMMAN S (1996) Flavonoids- chemistry, metabolism, cardio-protective effects, and dietary sources. Nutr Biochem 7: 66-76

CSALLANY AS, HEE-LEE J, SHOEMAN DW (2002) Protection of superoxide-induced cholesterol oxidation by antioxidants in protic conditions. Int $\mathrm{J}$ Food Sci Nut. 53: 403-409

DAS NP, PEREIRA TA (1990) Effects of flavonoids on thermal autoxidation of palm oil: Structure-activity relationship. J Am Oil Chem Soc 67: 255-258

DIONISI F, GOLAY PA, AESCHLIMANN JM, FAY B (1998) Determination of cholesterol oxidation products in milk powders: methods comparison and validation. J Agric Food Chem 46: 2227-2233

DREVON CA, WEINSTEIN DB, STEINBERG D (1980) Regulation of cholesterol esterification and biosynthesis in monolayer cultures of normal adult rat hepatocytes. J Biol Chem 255: 9128-9137

DU M, AHN DU (2000) Effects of antioxidants and packing on lipid and cholesterol oxidation and color changes of irradiated egg yolk powder. J Food Sci 65: 625-629

EDWARDS PA, ERICSSON J (1999) Sterol and isoprenoids: signaling molecules derived from the cholesterol biosynthetic pathway. Ann Rev Biochem 68: $157-185$

EMMANUEL HA, HASSEL CA, ADDIS PB, BERGMANN SD, ZAVORAL JH (1991) Plasma cholesterol oxidation products (oxysterols) in human subjects fed a meal rich in oxysterols. J Food Sci 56: 843-847

FITCH-HAUMANN B (1990) Antioxidants. Firm seeking products they can label as "natural". INFORM 1: $1002-1013$

FRAGA C, MARTINO V, FERRARO G, COUSSIO J, BOVERIS A (1987) Flavonoids as antioxidants evaluated by in vitro and in situ chemiluminescence. Biochem Pharmacol 36: 717-721

GALOBART J, GUARDIOLA F, BARROETA AC, LÓPEZ-FERRER S, BAUCELLS MD (2002) Influence of dietary supplementation with $\alpha$ tocopheryl acetate and canthaxantin on cholesterol oxidation in $\omega 3$ and $\omega 6$ fatty acid-enriched spraydried eggs. J Food Sci 67: 2460-2466

GARCÍA JA, MARASCHIELLO C (1997) Procedure for the determination of eight cholesterol oxides in poultry meat using column and solvent venting capillary gas chromatography. J Chromatog A: 764: 279-293

HAVSTEEN B (1983) Flavonoids, a class of natural products of high pharmacological potency. Biochem Pharmacol 32: 1141-1148

HEIM K, TAGLIAFERRO A, BOBILYA D (2002) Flavonoid antioxidants: chemistry, metabolism and structure-activity relationships. J Nutr Biochem 13: $572-584$
HUBER KC, PIKE OA, HUBER CS (1995) Antioxidant inhibition of cholesterol oxidation in a spray-dried food system during accelerated storage. J Food Sci 60: 909-916

ISHIBASHI S, SCHWARZ M, FRYKMAN PK, HERZ J, RUSSELL DW (1996) Disruption of cholesterol $7 \alpha$ hydroxylase gene in mice I: postnatal lethality reversed by bile acid and vitamin supplementation. J Biol Chem 271: 18017-18023

JAVITT NB (1990) 26-hydroxycholesterol: synthesis, metabolism, and biological activities. J Lipid Res 31: $1527-1533$

KIM SK, NAWAR WW (1991) Oxidative interactions of cholesterol with triacylglycerides. J Am Oil Chem Soc 68: 931-934

KORAHANI V, BASCOUL J, CRASTES DE PAULET A (1982) Autoxidation of cholesterol fatty acid esters in solid state and in aqueous dispersion. Lipids 17: 703708

KUBOW S (1993) Lipid oxidation products in food and atherogenesis. Nut Rev 51: 33-40

KUSHUHARA H, SHIMADA O, INUI J (1992) Effect of 25-hydroxycholesterol on cholesterol ester formation in Caco-2 cells. Lipids 27: 478-480

LACHANCE PA, ZEINA BS, JEONG WS (2001) Antioxidants: an integrative approach. Nutrition 17: 835-842

LAMPI AM, KATAJA L, KAMAL-ELDIN A, VIENO P (1999) Antioxidant activity of alpha- and gammatocopherols in the oxidation of rape seed oil triacylglycerols. J Am Oil Chem Soc 76: 749-755

LEE JH, SHOEMAN DW, KIM SS, CSALLANY AS (1977) The effect of superoxide anion in the production of seven major cholesterol oxidation products in aprotic and protic conditions. Int J Food Sci Nutr 48: 151-159

LEHMANN JM, KLIEWER SA, MOORE LB (1997) Activation of nuclear receptor LXR by oxysterols defines a new hormone response pathway. J Biol Chem 272: 3137-3140

LELAND LS, JOHNSON B (1989) Biological activities of oxysterols. Free Rad Biol Med 7: 285-332

LEONARDUZZI G, SOTTERO B, GALLI G (2002) Oxidized products of cholesterol: dietary and metabolic origin, and proatherosclerotic effects (review). J Nutr Biochem 13: 700-710

LI S, CHERIAN S, AHN D, HARDIN R, SIM J (1996) Storage, heating, and tocopherols affect cholesterol oxide formation in food oils. J Agric Food Chem 44: 3830-3834

LICHTENSTEIN AH, BRECHER P (1983) Esterification of cholesterol and 25-hydroxycholesterol by rat liver microsomes. Biochem Biophys Acta 751: 340-348

LIN CY, MOREL DW (1996) Esterification of oxysterols in human serum: effects on distribution and cellular uptake. J Lipid Res 37: 168-178

LINSEISEN J, WOLFRAM G (1998) Absorption of cholesterol oxidation products from ordinary foodstuff in humans. Ann Nutr Metab 42: 221-230

LINSEISEN J, HOFFMANN J, RIEDL J, WOLFRAM G (1998) Effect of a single oral dose of antioxidant mixture (vitamin $\mathrm{E}$, and carotenoids) on the formation of cholesterol oxidation products after ex vivo LDL oxidation in humans. Eur J Med Res 3: 5-12

LOTITO S, FRAGA C (2000) Ascorbate protects (+)catequin from oxidation both in a pure chemical system and human plasma. Bio. Res 33: 151-157 
LUND E, BJÖRKHEM I (1995) Role of oxysterols in the regulation of cholesterol homeostasis: a critical review. Acc Chem Res 28: 241-249

LUU B, MOOG C (1991) Oxysterols: biological activities physicochemical studies. Biochimie 73: 1317-1320

MAERKER G (1987) Cholesterol autoxidation. Current status. J Am Oil Chem Soc 64: 387-392

MAERKER G, UNRUH J (1986) Cholesterol oxides I. Isolation and determination of some cholesterol oxidation products. J Am Oil Chem Soc 3: 767-770

MISSLER SR, WAISILCHUK BA, MERRITT C (1985) Separation and identification of cholesterol oxidation products in dried egg preparations. J Food Sci 50: 595-598

MORGAN JN, ARMSTRONG DJ (1992) Quantification of cholesterol oxidation products in egg yolk powder spray-dried with direct heating. J Food Sci 57: 43-45

MOREL D, LIN CY (1996) Cellular biochemistry of oxysterols derived from the diet or oxidation in vivo. Nut Biochem 7: 495-506

NIETO S, GARRIDO A, SANHUEZA J, LOYOLA L, MORALES G, LEIGHTON F, VALENZUELA A (1993) Flavonoids as stabilizers of fish oil: An alternative to the use of synthetic antioxidants. J Am Oil Chem Soc 70: 773-778

NOUROOZ-ZADEH J, APPELQVIST LA (1988) Cholesterol oxides in Swedish foods and food ingredients: milk powder products. J Food Sci 53: 7480

OKAMURA N, HARAGUCHI H, HASHIMOTO K, YAGI A (1994) Flavonoids in Rosmarinus Officinalis leaves. Phytochem 37: 1463-1466

OSADA K, KODAMA T, YAMADA K, SUGANO M (1993) Oxidation of cholesterol by heating. J Agric Food Chem 41: 1198-2002

OSTLUND R, RACETTE S, STENSON W (2002) Effects of trace components of dietary fat on cholesterol metabolism: phytosterols, oxysterols, and squalene. Nutr Rev 60: 349-359

PARK SW, ADDIS PB (1985) HPLC determination of C7 oxidized cholesterol derivatives in foods. J Food Sci 50: 1437-1441

PARK SW, ADDIS PB (1985) Capillary column gasliquid chromatography resolution of oxidized cholesterol derivatives. Anal Biochem 149: 275-283

PARK SW, ADDIS PB (1986) Identification and quantitative estimation of oxidized cholesterol derivatives in heated tallow. J Agric Food Chem 34: 653-659

PARK SW, ADDIS PB (1992) Methods of analysis of cholesterol oxides (Chap 3). In: PENG SK, MORIN R (eds) Biological effects of cholesterol oxides., Boca Raton, FL: CRC Press. pp 33-69

PENG SK, TAYLOR CB, HILL JC, MORIN RJ (1985) Cholesterol oxidation derivatives and arterial endotelial damage. Atherosclerosis 41: 395-402

POKORNY J (1991) Natural antioxidants for food use. Trends Food Sci Technol 2: 223-226

RIGOTTI A. (2000) Scavenger receptors and atherosclerosis. Biol Res 33: 97-103

ROBAK J, GRYGLEWSKI R (1988) Flavonoids are scavengers of superoxide radical. Biochem Pharmacol 37: 837-841

ROBINS SJ, BRUNENGRABER H (1982) Origin of biliary cholesterol and lecithin in the rat: contribution of new synthesis and preformed hepatic stores. J Lipid Res 23: 604-608
ROBINS SJ, FASULO J (1997) High density lipoproteins, but not other lipoproteins, provide a vehicle for sterol transport to bile. J Clin Invest 99: 380-384

RONG JX, SHEN L, CHANG YH, RICHTERS A, HODIS H, SEVANIAN A (1999) Cholesterol oxidation products induce vascular foam cell lesion formation in hypercholesterolemic New Zealand white rabbits. Arterioscler Thromb Vasc Biol 19: 2179-2188

ROUX C, WOLF C, MULLIEZ N, GAOUA W, CORMIER V, CHEVY F, CITADELLE, D (2000) Role of cholesterol in embryonic development. Am J Clin Nutr :71 (suppl) 1270S-1279S

SANDER BD, ADDIS PB, PARK SW, SMITH DE (1989) Quantification of cholesterol oxidation products in a variety of foods. J Food Protect 52: 109-114

SAUCIER SE, KANDUTSCH AA, TAYLOR FR, SPENCER TA, PHIRWA S, GAYEN AK (1985) Identification of regulatory oxysterols, 24(S), 25epoxycholesterol and 25-hydroxycholesterol, in cultured fibroblasts. J Biol Chem 260: 14571-14579

SCHROEPFER GJ (2000) Oxysterols: Modulators of cholesterol metabolism and other process. Physiol Rev 80: 361-563

SEVANIAN A, MCLEOD LL (1987) Cholesterol autoxidation in phospholipid membrane bilayers. Lipids 22: 627-636

SHOZEN K, OSHIMA T, USHIO H, TAKIGUSHI A, KOIZUMI C (1997) Effects of antioxidants and packing on cholesterol oxidation in processed anchovy during storage. Food Sci Technol-Lebensmittel Wissenschaft \& Technologie 30: 2-8

SMITH L (1996) Review of progress in sterol oxidation. Lipids 31: 453-438

SPECTOR AA, YOREK MA (1985) Membrane lipid composition and cellular function. J Lipid Res 26: 1015-1035

STAPRANS I, PAN XM, RAPP JH, FEINGOLD KB (1998) Oxidized cholesterol in the diet accelerates the development of aortic atherosclerosis in cholesterolfed rabbits. Arterioscler Throm Vasc Biol 18: $977-$ 983

STREULI RA, CHUNG JA, SCANU AM, YACHNIN S (1981) Serum lipoproteins modulate oxygenated sterol insertion into human red cell membranes. Sci 212: 1294-1296

TANAKA RD, EDWARDS PA, LAN S, FOGELMAN AM (1983) Regulation of 3-hydroxy-3-methylglutaryl coenzyme A reductase activity in avian myeloblasts. Mode of action of 25-hydroxycholesterol. J Biol Chem 258: $13331-13339$

TUCKEY RC (1992) Cholesterol side-chain cleavage by mitochondria from the human placenta. Studies using hydroxycholesterols as substrates. J Steroid Biochem Mol Biol 42: 833-890

URQUIAGA I, LEIGHTON F (2000) Plant polyphenol antioxidants and oxidative stress. Biol Res 33: 55-64

VALENCIA P, SOTOMAYOR C, GONZALEZ G (1999) Cholesterol effect on lipid phase and betahydroxybutyrate hydrogenase activity in unilamellar vesicles and in bovine heart mitochondria. Biol Res 32: R-177 (abstract)

VALENZUELA A (2002) Natural antioxidants: from food safety to health benefits. Biotechnol Feed Ind 18: 323-332

VALENZUELA A, MORGADO N (1999) Trans fatty acid isomers in human health and in the food industry. Biol Res 32: 273-287 
VALENZUELA A, NIETO S (1996) Natural and synthetic antioxidants: food quality protectors. Grasas \& Aceites 47: 186-196

VALENZUELA A, SANHUEZA J, NIETO S (2002) Effect of synthetic antioxidants on cholesterol stability during the thermal-induced oxidation of a polyunsaturated vegetable oil. J Am Oil Chem Soc In press

VALENZUELA A, SANHUEZA J, NIETO S $\left(2002^{\mathrm{a}}\right)$ Differential inhibitory effect of $\alpha-, \beta-, \gamma-$, and $\delta$ tocopherols, on the metal-induced oxidation of cholesterol in unilamellar phospholipid-cholesterol liposomes. J Food Sci 67: 2051-2055

VALENZUELA A, SANHUEZA J, ALONSO P, CORVARI A, NIETO S (2002b) Inhibitory action of conventional food-grade natural antioxidants and of natural antioxidants of new development on the thermalinduced oxidation of cholesterol. J Food Sci (Submitted)

VALENZUELA A, SANHUEZA J, NIETO S (2003) Natural antioxidants in functional foods: from food safety to health benefits. Grasas \& Aceites, In Press
VAN DE BOVENKAMP P, KOSMEIJER-SCHUIL, TG, KATAN MB (1988) Quantification of oxysterols in Dutch foods: eggs products and mixed diets. Lipids 23: 1079-1085

WU JW, LEE MH, HO CT, CHANG SS (1982) Elucidation of the chemical structure of natural antioxidants isolated from rosemary. J Am Oil Chem Soc 59: 339345

YEAGLE P L (1985) Cholesterol in the cell membrane. Biochim Biophys Acta 822: 267-287

YOSHIDA H, KAJIMOTO G, EMURA S (1993) Antioxidant effects of d-tocopherols at different concentrations in oils during microwave heating. $\mathrm{J}$ Am Oil Chem Soc 70: 989-995

ZHANG WB, ADDIS PB, KRICK TP (1992) Quantification of 5-alpha cholestane-3 beta, 5, 6-triol and other cholesterol oxidation products in fast food French fried potatoes. J Food Sci 57: 716-718 